\title{
Lack of conservation effort rapidly increases African great ape extinction risk
}

Sandra Tranquilli ${ }^{1,2}$, Michael Abedi-Lartey $^{3}$, Fidèle Amsini ${ }^{4}$, Luis Arranz ${ }^{5}$, Augustus Asamoah ${ }^{6}$, Ogunjemite Babafemi ${ }^{7}$, Nsengiyunva Barakabuye ${ }^{4}$, Geneviève Campbell ${ }^{2}$, Rebecca Chancellor ${ }^{8,9}$, Tim R.B. Davenport ${ }^{4}$, Andrew Dunn ${ }^{4}$, Jef Dupain ${ }^{10}$, Christina Ellis ${ }^{11}$, Gilles Etoga ${ }^{12}$, Takeshi Furuichi ${ }^{13,14}$, Sylvain Gatti ${ }^{15}$, Andrea Ghiurghi ${ }^{16}$, Elisabeth Greengrass ${ }^{17}$, Chie Hashimoto ${ }^{13}, 18$, John Hart ${ }^{19}$, Ilka Herbinger $^{20}$, Thurston C. Hicks ${ }^{2,21}$, Lars H. Holbech ${ }^{22}$, Bas Huijbregts ${ }^{12}$, Inaoyom Imong ${ }^{2,4}$, Noelle Kumpel ${ }^{23}$, Fiona Maisels ${ }^{4,24}$, Phil Marshall ${ }^{25}$, Stuart Nixon ${ }^{23}$, Emmanuelle Normand ${ }^{20}$, Léonidas Nziguyimpa ${ }^{26}$, Zacharie Nzooh-Dogmo ${ }^{12}$, David Tiku Okon ${ }^{12}$, Andrew Plumptre ${ }^{4}$, Aaron Rundus 8,27 , Jacqueline Sunderland-Groves ${ }^{4}$, Angelique Todd ${ }^{12}$, Ymke Warren ${ }^{4}$, Roger Mundry², Christophe Boesch ${ }^{2}$, \& Hjalmar Kuehl ${ }^{2}$

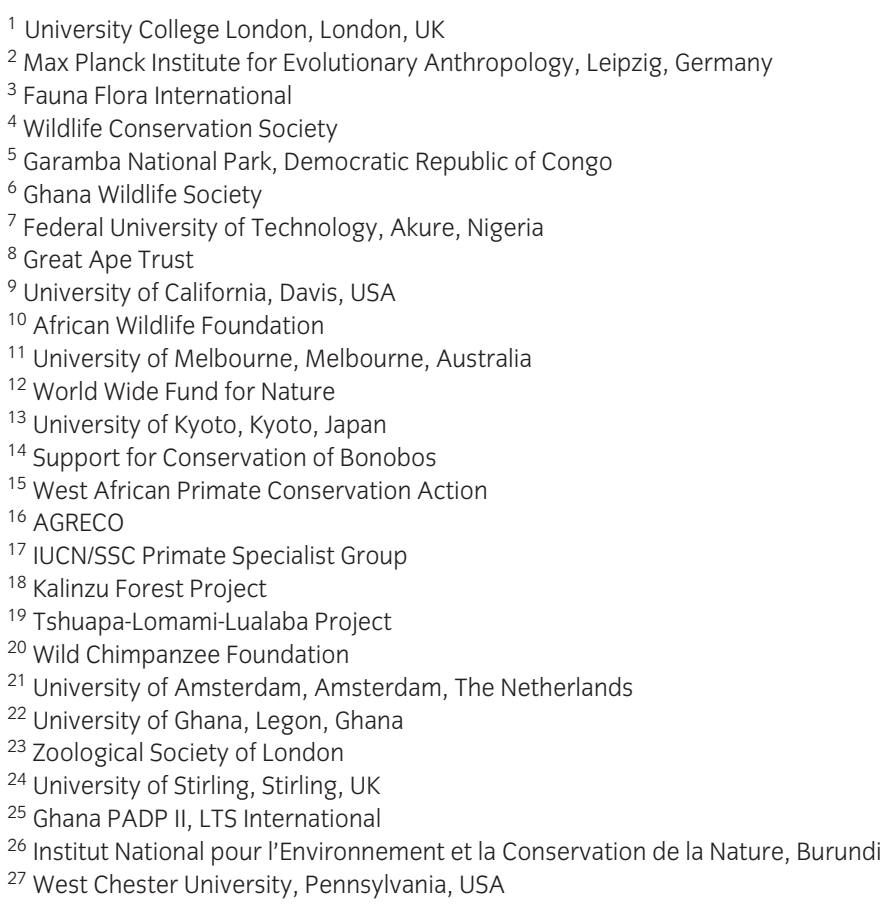

\section{Keywords}

African great apes; evidence-based

conservation; extinction risk; law enforcement; nongovernmental organizations; research; resource management areas, tourism.

\section{Correspondence}

Sandra Tranquilli, Max Planck Institute for Evolutionary Anthropology, Deutscher Platz 6, 04103 Leipzig, Germany. Tel: 0049 (0) 3413550 205; fax: 0049 (0) 3413550 299. E-mail:

sandra_tranquilli@eva.mpg.de

Received

6 July 2011

Accepted

2 November 2011

Editor

Sandra Tranquilli

doi: 10.1111/j.1755-263X.2011.00211.x

\begin{abstract}
A network of resource management areas (RMAs) exists across tropical Africa to protect natural resources. However, many are poorly managed and weakly protected. We evaluated how the lack of conservation effort influences the extinction risk of African great apes. We compiled information on presence/absence of primary (law enforcement guards) and secondary (tourism, research) conservation activities and nongovernmental conservation organizations (NGOs) support for 109 RMAs over the last 20 years. Along with these data, we collected environmental and anthropogenic variables, including recent records of ape presence/absence for all RMAs. As expected, law enforcement as a primary activity was the best predictor of ape survival rather than tourism or research as secondary activities. Furthermore, long-term NGO support had a significant positive influence on ape persistence. Our study demonstrates the feasibility of evaluating the relative importance of different conservation activities, an important step towards more evidence-based approaches in ape conservation.
\end{abstract}




\section{Introduction}

A network of resource management areas (RMAs) has been established for the purpose of protecting and conserving natural resources including wildlife, timber, and water supplies. RMAs are formally recognized by governments of the countries in which they occur, but sometimes also by international organizations or agencies. They are subject to different types of management strategies that vary according to the type of site and to differences in national policy (focused on either wildlife conservation or the extractive use of specific natural resources, or both; IUCN 1992; Chape et al. 2008). In Africa, the effectiveness of wildlife protection varies greatly across RMAs, with some being very effective and others being almost entirely ineffective with poor or absent protection measures causing wildlife population decline (Bruner et al. 2001; Craigie et al. 2010).

Limited or nonexistent conservation activities in different African nations arise from a number of factors, such as political and socioeconomic instability, corruption, lack of funding and capacity, poor environmental protection policies or poor will to enforce and to follow law policies (Plumptre et al. 2001; Smith et al. 2003; Struhsaker et al. 2005). Conservation efforts also frequently fail because of short-term funding of projects with long-term objectives (Oates 1999).

The vulnerability of RMAs is further amplified by different anthropogenic pressures. Rapidly increasing human population density and accelerated population growth at the borders of these areas, accompanied by the increasing incidence of poaching and other illegal activities, are causing declines in wildlife populations (Oates 1999; Brashares et al. 2001; Walsh et al. 2003; Wittemyer et al. 2008). The rapid loss of habitat in and around RMAs, caused by the expansion of deforestation and natural resource exploitation, increases the degree of isolation of important wildlife areas and has an additional negative influence on biodiversity (DeFries et al. 2005).

Fundamental for an RMA is the implementation of activities that enforce the laws that provide the legal framework for natural resources protection (Bruner et al. 2001; Hilborn et al. 2006; Fischer 2008). The delimitation of RMA boundaries, the prevention and prosecution of illegal actions, and the regulation of RMA access, are some of the activities conducted by law enforcement guards employed for RMA protection. Ideally, law enforcement guards and their activities provide the basis for effective wildlife and other natural resources protection that are then complemented by additional activities to mitigate tensions that often arise when RMAs are created.
These activities, such as environmental education, community development, tourism programs or research can provide benefits and socioeconomic development to a RMA region (Wrangham \& Ross 2008). Local and international governmental and nongovernmental organizations (GOs and NGOs, respectively) are frequently involved in the management of protected areas and frequently give their support to ensure the efficient implementation of conservation activities (Struhsaker et al. 2005).

The benefits of different conservation efforts, over the long-term and a large spatial scale, have rarely been compared in a quantitative manner with the aim of evaluating how well a particular conservation strategy reduces species extinction risks. This evidence-based approach, which has only recently been proposed, provides an important objective measure of success and potentially robust support for conservation efforts' effectiveness on the ground (Pullin \& Knight 2003). Given the recent decline in many African great ape populations (Walsh et al. 2003; Campbell et al. 2008; Greengrass 2009; Gatti 2009; Plumptre et al. 2010), it is crucial to determine which factors might influence their persistence or extinction within RMAs to help direct conservation efforts.

Here, we use an evidence-based approach to provide a continent-wide assessment of the relative significance of four different types of conservation efforts. We considered these either as primary (law enforcement guards), secondary (tourism, research) or other conservation efforts (NGO). We assessed their effects in 109 tropical African RMAs for the survival of African great apes.

Our results show that absence of law enforcement guards is the most influential risk for ape disappearance, rather than absence of the secondary conservation activities such as tourism and research. Moreover, ape persistence was significantly positively influenced by presence of NGO support. Thus, this study evaluates evidence of the benefits of conservation efforts for great apes for the first time on a continental scale.

\section{Methods \\ Data collection}

We collected historic and current records on the presence or absence of chimpanzees, bonobos, and gorillas in 109 RMAs between 1990 and 2009, the initial data being that apes were present in all the RMAs considered (Fig. 1; Table S1). These data were collected from published and unpublished literature on great ape studies, biodiversity surveys, and park management reports.

The category status of the RMAs used in the analysis focused on the conservation of wildlife and/or extractive 


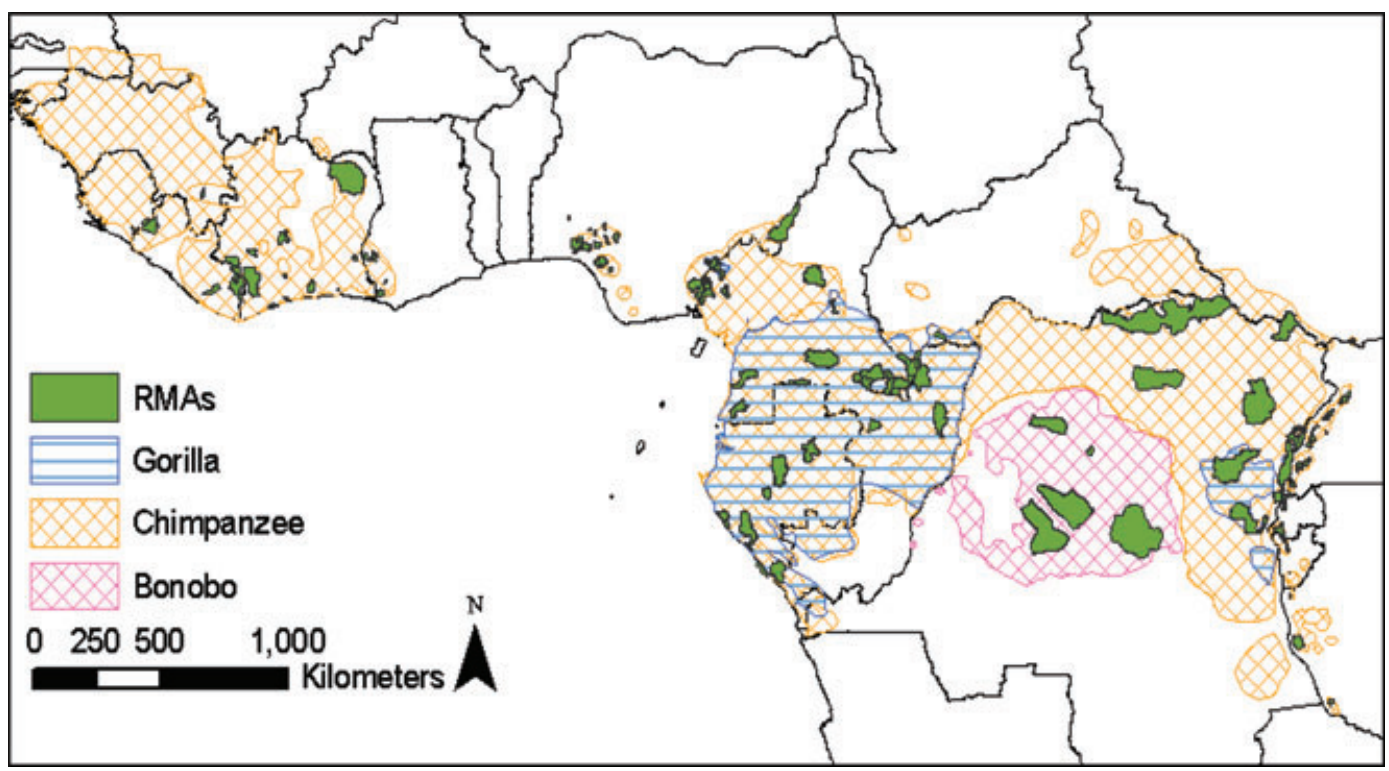

Figure 1 Distribution of the 109 RMAs selected for this study (GIS layers downloaded from WDPA: http://www.wdpa.org/), and the potential geographical ranges of the African great apes (layer kindly provided by L. Williamson, IUCN) (Cross river gorilla geographical range, between Southeast Nigeria and Southwest Cameroon, is not visible due to the scale of the map).

resources (e.g., timber, water supplies). We decided to include RMAs not specifically aiming at wildlife protection because we wanted to assess the impact of conservation activities rather than the category of the RMA. The dataset included only locations where apes occurred at the time of establishment of the RMA and where at least 2 years worth of data on ape persistence or absence/nearto-extinction status were available. Furthermore, we included only RMAs for which historical records of the presence or absence of conservation efforts within the considered period were available. RMAs, where ape status was recorded as absent/near-to-extinction and where appropriate survey effort was undertaken, were defined as sites where there was no record of ape presence during the last field survey (14 RMAs localized in Ghana, Nigeria and Côte d'Ivoire). Such a definition does not preclude the presence of a few remaining individuals, as some documented "extinctions" in the past have proven not to be the case (McGraw \& Oates 2002).

The RMAs were located within 16 countries in East, West, and Central Africa covering a geographical area of almost $280,000 \mathrm{~km}^{2}$. This represents approximately $68 \%$ of the total RMAs where great ape presence had been confirmed in the past. The size of the areas ranged from $1.2 \mathrm{~km}^{2}$ to $33,346.0 \mathrm{~km}^{2}$, with the duration under protection ranging from 2 to 84 years.

We collected records on presence and absence of conservation efforts for each RMA for the period with available records on apes. Conservation efforts included support by national and international NGOs, and activities including the presence of law enforcement guards (a primary conservation activity, acting directly on the ground), research, and tourism (both secondary conservation activities, whose actions are indirect but supportive). NGOs considered in this analysis were working for the protection of the area with different program objectives focused on education, wildlife protection, sustainable use of natural resources, scientific research, and tourism. Gaps in information for specific RMAs were filled with replies from questionnaires presented to park managers and researchers who worked at these sites.

\section{Analytical methods}

\section{Predictor variables and models}

We used Generalized Linear Mixed Models (GLMMs, Baayen 2008) with binomial error structure and logit link function to evaluate the relative importance of 10 different predictor variables on the overall status of apes (presence/near-to-extinction) in RMAs (see Table 1 for a description of test and control variables and their sources; and the appendix for a detailed description of the analysis). We also included as a predictor variable the interaction between the proportion of years with conservation efforts over the years considered and human population density around the RMA, assuming that the effectiveness of conservation efforts on ape persistence might vary according to the surrounding human population density. 
Table 1 Predictor variables considered in the analyses. Predictors were divided into test variables $(* *)$ and control variables $(*)$. The squared GDP (Gross Domestic Product) per capita was included to consider the potential nonlinear effect of country development on apes' survival. The years considered between 1990 and 2009 differed for each RMA according to the data availability on ape status and conservation efforts

\begin{tabular}{|c|c|c|}
\hline Predictor variable & Definition & Source \\
\hline RMA size* & Area in square kilometers & WDPA (http://www.wdpa.org/) \\
\hline Years of protection* & $\begin{array}{l}\text { Number of years since the establishment of the } \\
\text { conservation area until the most recent ape } \\
\text { record }\end{array}$ & Literature, questionnaires \\
\hline $\begin{array}{l}\text { Gross Domestic Product (GDP) per } \\
\text { capita and squared GDP* }\end{array}$ & Average GDP per capita over the years considered & $\begin{array}{l}\text { World Bank World Development Indicators } \\
\text { (http://data.worldbank.org/indicator) }\end{array}$ \\
\hline Armed conflicts* & $\begin{array}{l}\text { Proportion of years of armed conflicts inside the } \\
\text { ape country during the years considered }\end{array}$ & ACLED database (http://www.acleddata.com/) \\
\hline Human population density* & $\begin{array}{l}\text { Number of humans per square kilometer in a } \\
\text { buffer area of } 50 \mathrm{~km} \text { around the border of the } \\
\text { RMA in the last year of record }\end{array}$ & $\begin{array}{l}\text { Gridded Population of the World Version } 3 \\
\text { (http://sedac.ciesin.columbia.edu/gpw/) }\end{array}$ \\
\hline Degraded area* & $\begin{array}{l}\text { Percentage of degraded area in the RMA } \\
\text { recorded in } 2000\end{array}$ & $\begin{array}{l}\text { Global Land Cover } 2000 \\
\text { http://www-gem.jrc.it/glc2000) }\end{array}$ \\
\hline \multicolumn{3}{|l|}{ Conservation efforts** } \\
\hline Tourism sites** & $\begin{array}{l}\text { Proportion of years with tourism present in the } \\
\text { area (including tourist stations in and at the } \\
\text { border of the park) during the years considered }\end{array}$ & Literature, questionnaires, pers. comm. \\
\hline Research sites** & $\begin{array}{l}\text { Proportion of years with research station present } \\
\text { in the RMA during the years considered }\end{array}$ & Literature, questionnaires, pers. comm. \\
\hline Law enforcement guards** & $\begin{array}{l}\text { Proportion of years with guards present inside } \\
\text { the RMA during the years considered }\end{array}$ & Literature, questionnaires, pers. comm. \\
\hline $\begin{array}{l}\text { Nongovernmental organization } \\
(\mathrm{NGO})^{* *}\end{array}$ & $\begin{array}{l}\text { Proportion of years with local or international } \\
\text { NGO present and working for the protection of } \\
\text { the area permanently or semipermanently (>5 } \\
\text { months in a year) during the years considered }\end{array}$ & Literature, questionnaires, pers. comm. \\
\hline
\end{tabular}

The country where any given RMA was located was included as a random effect throughout.

We used five sets of predictor variables for the analysis. Each of these sets included all control variables (Table 1). In one set, we considered the four conservation efforts as equal parts of a single predictor variable, because the proportion of years with guards, research, tourism, and NGO presence were highly correlated with each other (Table S2). This "total conservation effort variable" depicts the proportion of years with any conservation effort present (we labeled models using this predictor variable as model $\left._{\text {TotConsEff }}\right)$. In the other four sets, we replaced the "total conservation effort variable" with one of the four conservation effort variables (proportion of years with presence of guards, NGOs, tourist or research sites) at a time (labeled as $\operatorname{model}_{\mathrm{GUARD}}, \operatorname{model}_{\mathrm{NGO}}$, model $_{\mathrm{TS}}$, and model $_{\mathrm{RS}}$, respectively). These models were built to evaluate the respective contribution of guards, research, tourism, and NGO presence on the probability of ape persistence. Some of the guards in our data set may have been employed for reasons not directly related to wildlife protection. Therefore, we ran an additional model in which we considered only the presence of guards employed for protecting wildlife ( model $_{\text {GUARD_WILDLIFE }}$ ).

\section{Datasets}

We based our analysis on two datasets: (1) an "incomplete dataset," where information on each conservation effort variable was not always available for each year of the period considered, and (2) a "complete dataset," a subset of the "incomplete dataset," where information on each conservation effort was available for each year of the period considered. These two datasets encompassed 109 and 82 RMAs, respectively, and were used to evaluate the significance of conservation efforts on ape persistence.

\section{Results \\ Overall conservation effort}

The first analysis, in which we considered presence of any conservation effort (presence of guards, NGOs, tourist, or research sites; model $\left._{\text {TotConsEff }}\right)$, revealed that the proportion of years with conservation effort had a marked effect on ape persistence (Tables 2 and 3). Specifically, lower proportions of years with conservation effort presence in a RMA lead to an increased probability of apes going extinct in that RMA (Fig. 2). In detail, the full model $_{\text {TotConsEff }}$ run for both datasets was clearly superior 
Table 2 Influence of the predictor variables on ape survival in 109 RMAs using the "incomplete dataset". The two derived terms were nonsignificant (squared GDP per capita estimate \pm SE $=4.99 \pm$ $3.75, z=1.3, P=0.18$, interaction between the proportion of years with conservation efforts and human density: estimate $\pm \mathrm{SE}=-2.23 \pm 2$, $z=-1.11, P=0.26)$ and removed from the model. No collinearity existed between the predictor variables (largest VIF: 2.073; average VIF: 1.665)

\begin{tabular}{lrrrr}
\hline & Estimate & SE & $z$ & $P$ \\
\hline Intercept & 3.945 & 0.897 & & \\
Years of protection & -0.159 & 0.593 & -0.269 & 0.788 \\
GDP per capita & -1.667 & 0.913 & -1.825 & 0.068 \\
Degraded area & -0.314 & 0.302 & -1.039 & 0.298 \\
Armed conflicts & -0.130 & 0.725 & -0.181 & 0.856 \\
RMA size & -0.313 & 0.598 & -0.524 & 0.600 \\
Human density & -1.480 & 0.593 & -2.496 & 0.012 \\
Conservation efforts & 1.895 & 0.646 & 2.931 & 0.003 \\
\hline
\end{tabular}

to the null model comprising only the random effect (likelihood-ratio test, incomplete dataset: $L R=29.36$, $\mathrm{df}=9, P=0.0006$; complete dataset: $\mathrm{LR}=30.36, \mathrm{df}=9$, $P=0.0004)$. In addition to the influence of total conservation effort, average Gross Domestic Product (GDP) per capita and human density had a significant negative effect on ape survival. No significant influence was evident for the other variables (Tables 2 and 3).

Multimodel inference revealed essentially the same findings. In fact, the proportion of years with any conservation effort present had the largest Akaike weight and was extremely well supported by the data (Table 4). As in the previous analysis GDP per capita and human density were also indicated as important factors determining ape persistence or extinction. To summarize, both analyses revealed the presence of any conservation effort to be

Table 3 Influence of the predictor variables on ape survival in $\mathbf{8 2}$ RMAs using the "complete dataset". The two derived terms were non significant (squared GDP per capita estimate $\pm \mathrm{SE}=0.34 \pm 1.58, \mathrm{z}=0.21$, $p=0.82$, interaction between the proportion of years with conservation efforts and human density: estimate $\pm \mathrm{SE}=-0.97 \pm 1.17, z=-0.82$, $P=0.40)$ and removed from the model. No collinearity existed between the predictor variables (largest VIF: 2.294; average VIF: 1.786)

\begin{tabular}{lrccc}
\hline & Estimate & SE & $z$ & $P$ \\
\hline Intercept & 4.467 & 1.448 & & \\
Years of protection & -0.138 & 0.751 & -0.184 & 0.854 \\
GDP per capita & -2.387 & 1.285 & -1.857 & 0.063 \\
Degraded area & -0.275 & 0.353 & -0.780 & 0.436 \\
Armed conflicts & -0.192 & 1.101 & -0.174 & 0.862 \\
RMA size & -0.267 & 0.618 & -0.433 & 0.665 \\
Human density & -1.623 & 0.779 & -2.083 & 0.037 \\
Conservation efforts & 2.400 & 0.867 & 2.770 & 0.006 \\
\hline
\end{tabular}

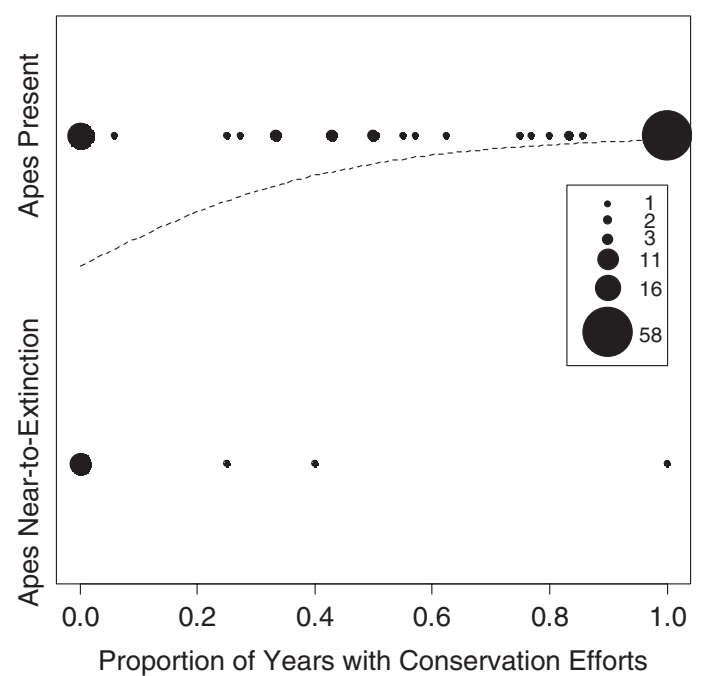

Figure 2 Ape persistence/extinction in relation to the proportion of years with conservation efforts present. The area of the circles corresponds to the number of RMAs. The curve represents the probability (as derived from a univariate logistic model) of apes to survive as a function of the proportion of years with conservation efforts present (guards, tourism and research, and NGOs).

the most important predictor of ape persistence among the variables investigated.

\section{Individual conservation efforts' effectiveness}

The second set of analyses, in which we considered the four individual conservation effort variables separately ( model $_{\mathrm{GUARD}}$, model $_{\mathrm{NGO}}$, model $_{\mathrm{TS}}$, model $_{\mathrm{RS}}$ ) revealed similar results as the first analysis (Table 5). In fact, the proportion of years with each particular conservation effort present had a positive and significant influence on ape persistence (Table 5).

The evaluation of the relative importance of the four different conservation effort measures revealed the proportion of years with NGO involvement and the

Table 4 Akaike weights for each predictor summed over all models that can be built out of the set of predictors. The $95 \%$ best model confidence set comprised 40 of 128 models and did not include the null model

\begin{tabular}{lc}
\hline Effect & Akaike weight \\
\hline Years of protection & 0.228 \\
GDP per capita & 0.721 \\
Degraded area & 0.363 \\
Armed conflicts & 0.249 \\
Human density & 0.845 \\
RMA size & 0.254 \\
Conservation efforts & 0.998
\end{tabular}


Table 5 Respective contribution of five types of conservation effort on the survival probabilities of great apes in RMAs. The mode/ ${ }_{\mathrm{RS}}$ and model $_{\text {GUARD_WILDLIFE }}$ revealed no stable assessment of the effect for proportion of years with research sites, and hence we had to establish its significance using likelihood-ratio tests comparing the full with a reduced model without this variable, which revealed $L R=8.00, d f=1, P=0.005$ and $L R=16.29$, $\mathrm{df}=1, P<0.0001$, respectively

\begin{tabular}{|c|c|c|c|c|c|c|c|c|c|}
\hline GLLMM'S & $\begin{array}{l}\text { Number } \\
\text { of RMAs }\end{array}$ & & $\begin{array}{l}\text { Cons. } \\
\text { effort }\end{array}$ & $\begin{array}{l}\text { Years of } \\
\text { protection }\end{array}$ & $\begin{array}{l}\text { GDP per } \\
\text { capita }\end{array}$ & $\begin{array}{c}\text { Degraded } \\
\text { area }\end{array}$ & $\begin{array}{c}\text { Armed } \\
\text { conflicts }\end{array}$ & $\begin{array}{l}\text { RMA } \\
\text { size }\end{array}$ & $\begin{array}{l}\text { Human } \\
\text { density }\end{array}$ \\
\hline \multirow[t]{2}{*}{ model $_{\text {GUARD }}$} & \multirow[t]{2}{*}{109} & $\begin{array}{l}\text { Estimate } \\
\text { (SE) }\end{array}$ & $\begin{array}{c}2.847 \\
(1.113)\end{array}$ & $\begin{array}{r}-0.015 \\
(0.560)\end{array}$ & $\begin{array}{r}-2.483 \\
(1.149)\end{array}$ & $\begin{array}{r}-0.329 \\
(0.287)\end{array}$ & $\begin{array}{r}-0.719 \\
(0.829)\end{array}$ & $\begin{array}{r}-0.086 \\
(0.571)\end{array}$ & $\begin{array}{r}-1.521 \\
(0.600)\end{array}$ \\
\hline & & Pvalue & 0.010 & 0.978 & 0.030 & 0.252 & 0.386 & 0.880 & 0.011 \\
\hline \multirow[t]{3}{*}{ model $_{\mathrm{TS}}$} & \multirow[t]{3}{*}{96} & Estimate & 2.188 & 0.231 & -1.254 & -0.728 & 0.231 & 0.399 & -1.669 \\
\hline & & (SE) & (1.083) & $(0.630)$ & $(0.866)$ & $(0.366)$ & $(0.685)$ & $(0.513)$ & $(0.634)$ \\
\hline & & $P$ value & 0.043 & 0.714 & 0.147 & 0.046 & 0.735 & 0.437 & 0.008 \\
\hline \multirow[t]{3}{*}{ model $_{\mathrm{RS}}$} & \multirow[t]{3}{*}{95} & Estimate & & 0.328 & -0.855 & -0.590 & 0.376 & 0.262 & -1.410 \\
\hline & & (SE) & $*$ & (0.594) & $(0.778)$ & $(0.323)$ & $(0.627)$ & $(0.522)$ & (0.555) \\
\hline & & $P$ value & & 0.581 & 0.271 & 0.067 & 0.548 & 0.615 & 0.011 \\
\hline \multirow[t]{3}{*}{ model $_{\mathrm{NGO}}$} & \multirow[t]{3}{*}{94} & Estimate & 2.078 & 0.010 & -1.623 & -0.296 & 0.036 & -0.196 & -1.484 \\
\hline & & (SE) & (0.682) & $(0.660)$ & $(1.024)$ & $(0.339)$ & $(0.805)$ & $(0.581)$ & $(0.673)$ \\
\hline & & $P$ value & 0.002 & 0.876 & 0.113 & 0.382 & 0.964 & 0.735 & 0.027 \\
\hline \multirow[t]{3}{*}{ model $_{\text {GUARD_WILDLIFE }}$} & \multirow[t]{3}{*}{109} & Estimate & & -0.189 & -2.091 & -0.266 & -0.286 & 0.218 & -1.243 \\
\hline & & (SE) & * & 0.585 & 1.089 & 0.286 & 0.767 & 0.516 & 0.526 \\
\hline & & $P$ value & & 0.746 & 0.050 & 0.429 & 0.708 & 0.671 & 0.018 \\
\hline
\end{tabular}

proportion of years with law enforcement guards to be clearly more effective than tourism and research. In fact, AIC-values demonstrated very similar support for the former two measures $\left(\mathrm{AIC}_{\mathrm{NGO}}=41.15, \mathrm{AIC}_{\text {Guards }}=42.18\right)$ whereas support for the latter two was clearly inferior $\left(\mathrm{AIC}_{\text {Tourism }}=48.65, \mathrm{AIC}_{\text {Research }}=53.40\right)$.

The additional model that we ran to evaluate the effect of guards employed to protect wildlife ( model $_{\text {GUARD_WILDLIFE }}$ ) revealed no stable result when evaluated in the same way, but revealed significance when compared to a model without this variable, using a likelihood-ratio test $(\mathrm{LR}=16.29, \mathrm{df}=1, P<0.0001)$.

\section{Discussion}

This study provides the first continent-wide analysis of the relative importance of conservation efforts aiming at the protection of African great apes. Our models clearly revealed that ape persistence in an RMA was highly positively influenced by the number of years with conservation effort, specifically NGO involvement and law enforcement guard presence, followed by secondary conservation activities, such as tourism and research. As expected, high human population density and national development, defined as GDP per capita, negatively influenced ape survival.

Our findings clearly confirm that guards are the primary enforcers of law and confirm the positive effect of their presence. It is likely, however, that we actually underestimated the effect that law enforcement guards can have because we did not consider the degree to which their activities and presence was effective in the RMA.

As a consequence, we consider our finding to be rather conservative and it seems likely that the actual effect of such activities is even larger than reported here. In fact, guards' effectiveness in situ performance is generally contingent upon their level of training, numbers per kilometer square, patrolling effort, resources, equipment, and salary (Leader-Williams et al. 1990; Jachmann 2008). These variables were not taken into consideration in this study because of insufficient data for most of the RMAs considered.

Our findings further suggest that the long-term presence of both tourism and research stations is a positive additional investment for the conservation of great apes. Both activities are relevant for promoting local employment and raising awareness (Davenport et al. 2002; Wrangham \& Ross 2008). Tourism, in particular, can generate significant economical income for both the RMA and the local community (Davenport et al. 2002). However, many countries do not have an established tourism industry and are challenged to successfully develop one for a variety of reasons including political instability, high corruption, and limited logistics and infrastructure, or harsh conditions that make wildlife viewing unattractive to tourists.

Nevertheless, permanent tourism and research stations play an important role in creating wildlife refugia, even if this only applies to limited areas inside an RMA, by reducing hunting and other destructive human activities 
that put pressure on wildlife populations (Wrangham \& Ross 2008; Campbell et al. 2011).

The positive role of long-term local and international NGO presence is often attributed to their technical and/or financial support of different conservation programs and their activities that assist RMA management (Struhsaker et al. 2005). The four types of conservation effort that were considered in this study may enhance one another either in a bidirectional way (i.e., the presence of one supports the presence of the other and vice versa) or in a unidirectional way (i.e., the presence of one variable supports the presence of the other but not vice versa). This might explain the high correlation found between the different conservation effort variables.

Several of the incorporated control variables (RMA size, years of protection, armed conflicts, and degraded area) were not or barely found to be significant. This was partly surprising because armed conflicts, RMA size, and degraded areas are known to influence wildlife survival. However, for armed conflicts it is known that their effect on wildlife is very context specific (Blom $\delta$ Yamindou 2001; Glew \& Hudson 2007). With regard to RMA size, it seems possible that the negative impact of smaller areas was overridden by conservation activities, and furthermore potentially not detectable during the short period considered in this study. The lack of an effect of percentage degraded area might be an artifact of poor data quality, because we used data from year 2000 regardless of which period we actually considered (because of lack of comparable data for other years). Hence, it seems plausible that better data on habitat degradation would reveal a clear effect of this variable.

We found that high human population densities and national economic development had negative effects in this study. Past case studies focusing on these variables have given detailed explanations of their significant negative influence on wildlife populations (James 1994; Oates 1999; Blom et al. 2005). Interestingly, in our study human population density and GDP (as well as all others variables investigated) seemed less important determinants of ape survival than conservation effort. However, one would expect that conservation efforts become more important to ensure ape survival with increasing economic development (GDP). Therefore, the absence of a significant interaction between human population density and conservation effort could be explained by the fact that human population density was an inappropriate proxy for the actual threats humans cause (e.g., differences in attitude towards wildlife in different ethnic or religious groups).

In conclusion, this study points out once more the importance of law enforcement as the primary conservation activity on the ground for wildlife survival. What specifically determines the extent to which a given law enforcement measure is effective was beyond the scope of this study. Nevertheless, there still seems considerable debate about what strategies might be optimal to overcome the issues preventing the implementation of successful law enforcement (e.g., investment in education of guards, manpower, equipment, and communication facilities or identification of effective patrolling schemes). Hence, we encourage the application of an evidencebased approach for the quantitative assessment and evaluation not only of different law enforcement schemes, but also of other conservation approaches and strategies. Continuous and rigorous monitoring of wildlife populations and their threats should guide patrol efforts and aid in the evaluation of different protection activities to ensure that ape populations persist in the long-term.

\section{Acknowledgments}

This study was supported by the Arcus Foundation, the Max Planck Society and the U.S. Fish and Wildlife Service. We thank Richard Bergl, Dieudonné Bizimana, Nico Dauphine, Pascal Descheres, Ofir Drori, Chris Duvall, Atanga Ekobo, Anna Feistner, Nicolas Granier, Maryke Gray, David Greer, Daniel Hanni, Chloe Hodgkinson, Magnus Mosha, Anna Ntongho, Jefferson Hall, Terese Hart, Fidelis Manga, Laura Martinez, Alastaire McNeilage, Bethan Morgan, David Morgan, Leonard Mubalama, Paul N'Goran, Aaron Nicholas, Radar Nishuli, Manasseh Eno $\mathrm{Nku}$, Alain Nouredine, John Oates, Alex Piel, Charles Petre, Martha Robbins, Carol Rowney, Crickette Sanz, and Nikki Tagg. Finally, we thank three anonymous referees' for their helpful comments.

\section{Supporting Information}

Additional supporting information may be found in the online version of this article, including Supplementary Methods and References.

Table S1: List of the 109 RMAs and the latest year of ape record. The management category of these RMAs differs in and among different countries (similar categories names among different countries often do not imply that they share same management objectives).

Table S2: Pearson correlations between the conservation effort variables

Please note: Wiley-Blackwell is not responsible for the content or functionality of any supporting materials supplied by the authors. Any queries (other than missing material) should be directed to the corresponding author for the article. 


\section{References}

Baayen, R.H. (2008) Analyzing linguistic data. Cambridge University Press, Cambridge.

Blom, A., Yamindou J. (2001) A brief history of armed conflict and its impact on biodiversity in the Central African Republic. Biodiversity Support Program, Washington, D.C.

Blom, A., van Zalinge R., Heitkoenig I.M.A., Prins H.H.T. (2005) Factors influencing the distribution of large mammals within a protected central African forest. Oryx 39, 381-388.

Brashares, J.S., Arcese P., Sam M.K. (2001) Human demography and reserve size predict wildlife extinction in West Africa. Proc R Soc Lond B 268, 2473-2478.

Bruner, A.G., Gullison R.E., Rice R.E., da Fonseca G.A.B. (2001) Effectiveness of parks in protecting tropical biodiversity. Science 291, 125-128.

Campbell, G., Kuehl H., Diarrassouba A., N'Goran P.K., Boesch C. (2011) Long-term research sites as refugia for threatened and over-harvested species. Bio Lett 7, 723-726.

Campbell, G., Kuehl H., N'Goran Kouame P., Boesch C. (2008) Alarming decline of West African chimpanzees in Cote d'Ivoire. Curr Biol 18, 903-904.

Chape, S., Spalding M., Jenkins, S. (2008) The World's Protected Areas: status, value and prospects in the $21^{\text {st }}$ century. UNEP-WCMC, Cambridge.

Craigie, I.D., Baillie J.E.M., Balmford A. (2010) Large mammal population declines in Africa's protected areas. Biol Cons 143, 2221-2228.

Davenport, L., Brockelman W.Y., Wright P.C., Ruf K., Rubio del Valle F.B. (2002). Ecotourism tools for parks. Pages 279-306 in J. Terborgh, C. van Shaik, L. Davenport, M. Rao, editors. Making parks work. Island Press, Washington, DC.

DeFries, R., Hansen A., Newton A.C., Hansenm M.C. (2005) Increasing isolation of protected areas in tropical forests over the past twenty years. Ecol Appl 15, 19-26.

Fischer, F. (2008) The importance of law enforcement for protected areas. don't step back! be honest-protect! Gaia 17, 101-103.

Gatti, S. (2009) Status of primate populations in protected areas targeted by the community forest biodiversity project. WAPCA Ghana report.

Glew, L., Hudson M.D. (2007) Gorillas in the midst: the impact of armed conflict on the conservation of protected areas in sub-Saharan Africa. Oryx 41, 140-150.
Greengrass, E.J. (2009) Chimpanzees are close to extinction in southwest Nigeria. Prim Cons 24, 77-83.

Hilborn, R., Arcese P., Borner M. et al. (2006) Effective enforcement in a conservation area. Science $\mathbf{3 1 4}$, 1265-1266.

IUCN. (1992) Protected Area of the World: A Review of National Systems. Volume 3: Afrotropical. IUCN, Gland, Switzerland and Cambridge, UK.

Jachmann, H. (2008) Monitoring law-enforcement performance in nine protected areas in Ghana. Bio Cons 141, 89-99.

James, P.C. (1994) On economic growth and ecological decay. Cons Bio 8, 1161-1162.

Leader-Williams, N., Albon S.D., Berry P.S.M. (1990) Illegal exploitation of black rhinoceros and elephant populations: patterns of decline, law enforcement and patrol effort in Luangwa Valley, Zambia. J Appl Eco 27, 1055-1087.

McGraw, W.S., Oates J.F. (2002) Evidence for a surviving population of Miss Waldron's red colobus. Oryx 36,223.

Oates, J. (1999) Myth and Reality in the Rain Forest. University of California Press, Berkeley.

Plumptre, A., Masozera M., Vedder A. (2001) The impact of war on the conservation of protected areas in Rwanda. Biodiversity Support Program, Washington, DC.

Plumptre, A.J., Rose R., Nangendo G. et al. (2010) Eastern Chimpanzee (Pan troglodytes schweinfurthii): Status Survey and Conservation Action Plan 2010-2020. IUCN, Gland, Switzerland.

Pullin, S.A., Knight T.M. (2003) Support for decision making in conservation practice: an evidence-based approach. J Nature Con 11, 2003, 83-90.

Smith, R.J., Muir R.D.J., Walpole M.J., Balmford A., Leader-Williams N. (2003) Governance and loss of biodiversity. Nature 426, 67-70.

Struhsaker T.T., Struhsaker P.J., Siex K.S. (2005) Conserving Africa's rain forests: problems in protected areas and possible solutions. Bio Cons 123, 45-54.

Walsh, P.D., Abernethy K.A., Bermejo M. et al. (2003) Catastrophic ape decline in western equatorial Africa. Nature 422, 611-614.

Wittemyer, G., Elsen P., Bean W.T., Coleman A., Burton, O., Brashares J.S. (2008) Accelerated human population growth at protected area edges. Science 321, 123-126.

Wrangham, R., Ross E. (2008) Science and Conservation in African forests: the benefit of long-term research. Cambridge University Press, Cambridge. 